\title{
Use of symptoms and signs to diagnose maxillary sinusitis in general practice: comparison with ultrasonography
}

\author{
N P van Duijn, H J Brouwer, H Lamberts
}

\begin{abstract}
Objective - To establish the incidence of maxillary sinusitis in general practice and the predictive value of symptoms and signs.

Design-Population based study.

Setting-9 general practices with 15220 patients aged 15 years and older on the list.

Patients $-\mathbf{4 0 0}$ patients with $\mathbf{4 4 1}$ episodes in whom practitioners intended to confirm or to exclude sinusitis.

Main outcome measures-Results of ultrasonography and signs and symptoms associated with positive results.

Results -212 of the 441 episodes were confirmed by ultrasonography. $15 \cdot 7$ episodes occurred per 1000 adults per year. The five symptoms beginning with common cold $(\beta$ coefficient $=1.035)$, purulent rhinorrhoea $(0.996)$, pain at bending $(0.950)$, unilateral maxillary pain $(0.640)$, and pain in teeth $(0.606)$ were associated with positive results on ultrasonography. General practitioners' clinical diagnoses were correct in 177 episodes, false positive in 88 , false negative in 22, and uncertain in 154. With an algorithm using the five weighted symptoms 243 of the diagnoses would have been correct, but 110 would remain uncertain and 44 cases would have been missed.
\end{abstract}

Conclusion-The five symptoms algorithm would improve diagnostic accuracy of general practitioners, but incorrect and uncertain diagnoses cannot be avoided.

\section{Introduction}

In general practice sinusitis is usually diagnosed on the basis of symptoms and signs, resulting in an incidence of 21 to 25 episodes per 1000 listed patients per year. ${ }^{1-4}$ Radiography is used in $14 \%$ of episodes and referrals occur in $7 \%$. Fever, a preceding upper respiratory tract infection, (unilateral) purulent rhinorrhoea, and unilateral maxillary pain are considered to be important for diagnosis. Cacosmia and purulent secretions from the antral ostium have a high predictive value, but occur only in $8 \%$ and $4 \%$ of cases respectively. ${ }^{5.9}$

Four methods are available to diagnose maxillary sinusitis objectively: radiography, computed tomography, ultrasonography, and invasive procedures. Of these methods, only ultrasonography is suitable for repeated use in general practice as part of a study. Ultrasonography does not affect the course of sinusitis and is ethical in healthy patients. The sensitivity and specificity of ultrasonography $(89 \%$ and $95 \%$ respectively $)^{10-13}$ are better than those of radiography of the maxillary sinus, $(77 \%$ and $80 \%) .{ }^{10-16}$ The sensitivity and specificity of ultrasonography of the frontal sinus are estimated to be $90 \%$ and $75-95 \%$ respectively. ${ }^{10-18}$ Ethmoiditis cannot be diagnosed by ultrasonography. Radiography is said to be unsuitable for ascertaining abnormalities in the ethmoid cells, ${ }^{19}$ though recently good validity has been reported. ${ }^{20}$

The purpose of this study was to establish the incidence of maxillary and frontal sinusitis in general practice as diagnosed by ultrasonography and the predictive value of symptoms and signs at the start of the episode. The clinical diagnosis of sinusitis by the participating general practitioners at the start of the episode was compared with ultrasonographic results. On the basis of the calculated predictive values of symptoms and signs an algorithm was produced to improve the accuracy of clinical diagnosis of sinusitis.

\section{Subjects and methods}

The study population consisted of patients aged 15 years and older $(n=15220)$ on the list of nine general practices who visited their doctor during 1 December 1987 to 1 December 1988. Patients were eligible when their doctor intended to carry out investigations to confirm or exclude sinusitis or to treat the episode as sinusitis. We tried to avoid underreporting caused by practitioners' or patients' lack of time for research. Firstly, it was emphasised that reporting some eligible but not included patients was better than an unknown bias in incidence and interdoctor variation. The number of cases per general practitioner and the number of reported but not included patients were monitored and fed back to the participating general practitioners. Secondly, we believe that social control by peers in a duty group of general practitioners is a good way to achieve adherence to research committments. Thirdly, the broad inclusion criterion "intention to diagnose" is straightforward and feasible in daily practice. Eligible but not included patients were reported by name and date. The consultations of these patients with the participating practitioner and the medical history were registered afterwards.

The nine participating practices (11 general practitioners, 20230 patients) provide primary care for a geographically well defined area with 23000 inhabitants. Compared with the whole Dutch population our study population showed overrepresentation of the 25 44 age group $(42 \% v 32 \%)$ and underrepresentation of both the $45-64$ years $(13 \% v 21 \%)$ and of 65 years and older $(8 \% v 13 \%)$ groups. Incidences specific for age were calculated from the average of the numbers of patients registered at the beginning and end of the study.

Patients visited the investigator's practice within one day after the first consultation with their general practitioner. The investigator, one of the 11 participating physicians, was responsible for diagnosis and treatment from then on. At each consultation the patient completed a questionnaire on nose complaints; general weakness; headache, including the localisation of the pain and pain severity; and symptoms such as coughing, cacosmia, anosmia, sore throat, and earache. A standardised physical examination was performed of the nose, throat, and face, specifically looking at pressure points of the maxilla (caudal side), frontal region, nasofrontal angle of the orbita, and the infraorbital and supraorbital nerves. The patient was asked to bend forward and report on pain or a feeling of pressure. At rhinoscopy the investigator looked for purulent secretions on the nasal floor, ostial secretions running over the concha inferior, septal 
deviations, and nasal polyps. The intraobserver variation of the assessment of septal deviations was calculated on the results of first and follow up consultations.

A-mode ultrasonography of maxillary and frontal sinuses was performed, not blinded, with the a Echosine 1000 with a probe of $3.5 \mathrm{MHz} \cdot{ }^{1011}$ The interobserver variation was calculated from the ultrasonographic results in 82 sinuses ( 41 patients) reported by two independent observers $(x=0 \cdot 72)$. The interobserver variation of the interpretation of the ultrasonogram was near zero (four observers, two results out of 200 ultrasonograms differed).

The investigator treated the patient as usual, with antibiotics or not, depending on course, symptom severity, and functional status. Treatment was thus not standardised and the course of the episode therefore reflected common experience. At each follow up the same procedures were repeated until the end of the episode, which was defined as resolving of complaints and normal results of investigations and ultrasonography. The investigator recorded a "clinical diagnosis" when the ultrasonographic results were negative and remained so during the episode. The need for radiography or referral to the ear, nose, and throat surgeon was decided on by the investigator. After treatment by the surgeon the patient was re-examined to ascertain the end of the episode.

We invited a sample of 100 patients, from the practice population, for investigation with the same procedures to establish the incidence of symptoms and signs in the non-consulting population. The patients were of similar age and sex to the study population; 71 agreed to investigation.

The 21 symptoms and 15 signs registered in consulting patients were analysed separately by the $\chi^{2}$ test. A p

TABLE I - Incidence of maxillary sinusitis per 1000 patients per age group per year ( $n=$ number of episodes)

\begin{tabular}{|c|c|c|c|c|c|}
\hline & \multicolumn{4}{|c|}{ Age (years) } & \multirow[b]{2}{*}{ All $\geqslant 15$} \\
\hline & $15-24$ & $25-44$ & $45-64$ & $\geqslant 65$ & \\
\hline Ultrasonography positive $(n=212)$ & $11 \cdot 1$ & $19 \cdot 6$ & 4.9 & 1.8 & $14 \cdot 1$ \\
\hline All eligible patients $(n=236)$ & $11 \cdot 7$ & $20 \cdot 6$ & $5 \cdot 1$ & 1.9 & $15 \cdot 7$ \\
\hline Sinusitis according to general practitioner $(\mathbf{n}=375)$ & $17 \cdot 1$ & $35 \cdot 3$ & $12 \cdot 9$ & $6 \cdot 2$ & $25 \cdot 3$ \\
\hline Morbidity study ${ }^{12}(n=1130)$ & $23 \cdot 2$ & $29 \cdot 4$ & $25 \cdot 4$ & $18 \cdot 2$ & $25 \cdot 0$ \\
\hline
\end{tabular}

TABLE II - Frequency of occurrence of symptoms and signs related to ultrasonographic results $(p<0 \cdot 10)$. Numbers (percentages) of episodes and likelihood ratio in study group (441 episodes, 212 positive on ultrasonography) and numbers (percentages) of sample from the practice population $(n=71)$

\begin{tabular}{|c|c|c|c|c|}
\hline & \multicolumn{2}{|c|}{ Ultrasonographic results } & \multirow{2}{*}{$\begin{array}{l}\text { Likelihood } \\
\text { ratio }\end{array}$} & \multirow{2}{*}{$\begin{array}{l}\text { Sample from } \\
\text { practice } \\
\text { population }\end{array}$} \\
\hline & Positive & Negative & & \\
\hline \multicolumn{5}{|l|}{ Complaints ${ }^{\star}:$} \\
\hline Beginning with common cold & $174(85)$ & $157(72)$ & $1 \cdot 4$ & Not applicable \\
\hline Purulent rhinorrhoea & $127(62)$ & $72(33)$ & 1.9 & $9(13)$ \\
\hline Hyposmia or anosmia & $113(55)$ & $98(45)$ & $1 \cdot 2$ & $5(7)$ \\
\hline Pain in teeth & $74(36)$ & $37(17)$ & $2 \cdot 1$ & \\
\hline Unilateral maxillary pain & $70(34)$ & $44(20)$ & 1.8 & \\
\hline Unilateral frontal pain & $51(25)$ & $33(15)$ & 1.7 & $2(3)$ \\
\hline \multicolumn{5}{|l|}{ Signs: } \\
\hline Pain at bending & $138(65)$ & $92(40)$ & $1 \cdot 6$ & $3(4)$ \\
\hline Maxillary pressure pain & $106(50)$ & $87(38)$ & $1 \cdot 3$ & $1(1)$ \\
\hline Purulent secretions in nasal floor & $34(16)$ & $21(9)$ & $1 \cdot 8$ & $2(3)$ \\
\hline Purulent secretions above concha inferior & $15(7)$ & $5(2)$ & $3 \cdot 3$ & \\
\hline Nasal polyp & $4(2)$ & $2(1)$ & $2 \cdot 2$ & \\
\hline Purulent postnasal drip & $6(3)$ & $1(0 \cdot 5)$ & $6 \cdot 5$ & \\
\hline
\end{tabular}

${ }^{\star}$ Complaints are based on 423 episodes ( 205 positive on ultraonography) because of 18 missing questionnaires.

TABLE III -Symptoms independently associated with ultrasonographic results: frequencies in the study population $(n=423), \beta$ coefficients, and standard errors from logistic regression

\begin{tabular}{lcccc}
\hline & $\begin{array}{c}\text { Frequency } \\
(\%)\end{array}$ & $\beta$ coefficient & SE & Weight \\
\hline Constant $\alpha_{0}$ & & $-2 \cdot 124$ & 0.288 & -6 \\
Beginning with common cold & 78 & 1.035 & 0.261 & 3 \\
Purulent rhinorrhoea & 47 & 0.996 & 0.221 & 3 \\
Pain at bending & 52 & 0.950 & 0.220 & 3 \\
Unilateral maxillary pain & 27 & 0.640 & 0.265 & 2 \\
Pain in teeth & 26 & 0.606 & 0.266 & 2 \\
\hline
\end{tabular}

value of more than $0 \cdot 10$ excluded an association with the ultrasonographic results. Symptoms and signs that were associated were analysed by logistic regression to establish the independent likelihood of sinusitis for patients with one or more of these symptoms. ${ }^{21}$ These results were used to produce an algorithm to improve the accuracy of clinical diagnosis. The data were entered and managed in a SIR/DBMS database (SIR/DBMS version 2.2. Deerfield: Documentation Librarian SIR, 1987). Statistical analysis was performed with SPSS/PC+ (version 3.1).

\section{Results}

During the registration year 400 patients were included with 441 episodes. Thirty six patients had recurrent episodes, five of whom had three episodes. Sinusitis was established by ultrasonography in 212 of the episodes (110 were bilateral). The incidence of maxillary sinusitis proved by ultrasonography for patients aged 15 years and older was $14 \cdot 1$ episodes per 1000 patients on the list per year (table I). One patien had maxillary as well as frontal sinusitis, without consequences for course and outcome. Fifty eligible but not included patients were reported, mostly for lack of time on the side of the practitioner or the patient. Sometimes coexistent illness made it impossible for patients to attend the investigator's practice (15 patients). Only four patients refused to participate. The patients not included were comparable with the study group with respect to age, history of ear, nose, and throat procedures, previous sinusitis episodes, psychological and social problems, long term diseases and medication, the number of consultations per year, and interdoctor variation. Men were overrepresented ( $42 \% v 31 \%$ in the study group). The general practitioner consultations of the patients not included showed no important differences from those of the study group: the reasons for consultation and complaints were similar, but fewer of the not included patients had a clinical diagnosis of sinusitis $(55 \% v$ $85 \%)$. If half of the eligible but not included patients are added the incidence of sinusitis can be estimated to be 15.7 per 1000 patients aged 15 years and older per year.

In cases where ultrasonography gave negative results the clinical diagnoses were upper respiratory tract infection (71), allergic or chronic hyperreactive rhinitis (57), headache (49), and other (49). In $6 \%$ of the episodes in the first half of the registration year the patient had a recurrence within six months. One patient had chronic maxillary sinusitis at antroscopy with sinus polyps, asthma, and aspirin sensitivity. Persistent complaints at the end of the episode occurred more often, in $10 \%$ of all episodes. Half of these patients had chronic headache and nose complaints independent of the sinusitis. The other half of the patients with persistent complaints had maxillary cysts, polyps, or persistent sinusitis. In 26 of the 441 episodes the patient was referred to the ear, nose, and throat surgeon ( 24 patients with at least once a positive result on ultrasonography); 10 of these patients required an invasive procedure. One person included in the sample from the practice population had positive results on ultrasonography with minor headache and nose complaints.

Of the 21 complaints and 15 signs recorded at the start of the episodes, 12 could be related to the ultrasonographic results $(\mathrm{p}<0 \cdot 10)$ (table II). Three rare findings (average occurrence $<5 \%$, table II). were not included in the further analysis. Of the remaining nine symptoms entered in the logistic regression, five were independently related to ultrasonographic results (table III). Unilateral frontal pain, purulent secretions in nasal floor, hyposmia or anosmia, and maxillary 
pressure pain were not significantly related after logistic regression. Unilateral frontal pain occurred more often in patients with sinusitis than in others (table II) but logistic regression showed that frontal pain was dependent mostly on unilateral maxillary pain. Unilateral and bilateral frontal pain together were found in $80 \%$ of the sinusitis patients, $60 \%$ of the remaining patients, and $15 \%$ of the random sample from the practice population. The result of physical examination and maxillary, frontal, and nasofrontal pressure pain were also dependent on unilateral maxillary pain.

The likelihood ratios for sinusitis with any combination of symptoms were calculated from the results of the logistic regression procedure..$^{21}$ These ratios were then used to assess the accuracy of the proposed algorithm in diagnosing sinusitis.

Algorithm - The five symptoms are weighted according to the coefficients from the logistic regression procedure, and a likelihood ratio is calculated. If the ratio is lower than 0.75 sinusitis is excluded, if the ratio is $0 \cdot 75-1 \cdot 25$ the diagnosis is uncertain, and if it is above 1.25 the diagnosis is established.

Diagnosis with the algorithm was more accurate than the clinical diagnosis by general practitioners at the start of the episode (table IV). A considerable proportion of the diagnoses remained uncertain with the algorithm.

TABLE IV-Accuracy of the clinical diagnoses of general practitioners and diagnosis using algorithms based on five weighted symptoms.* Weighing as given in table III

\begin{tabular}{lcccc}
\hline & \multicolumn{4}{c}{ No (\%) of diagnoses: } \\
\cline { 2 - 5 } & Uncertain & Correct & $\begin{array}{c}\text { False } \\
\text { negative }\end{array}$ & $\begin{array}{c}\text { False } \\
\text { positive }\end{array}$ \\
\hline $\begin{array}{c}\text { Clinical diagnoses by general } \\
\text { practitioners }\end{array}$ & $154(35)$ & $177(40)$ & $22(5)$ & $88(20)$ \\
$\begin{array}{c}\text { Algorithm (5 weighted } \\
\text { symptoms) }\end{array}$ & $110(25)$ & $243(55)$ & $44(10)$ & $44(10)$ \\
\hline
\end{tabular}

^Common cold, pain at bending, purulent nasal secretions, pain in teeth, and unilateral maxillary pain.

\section{Discussion}

In a well defined population the incidence of maxillary sinusitis, proved by ultrasonography was estimated at 15.7 per 1000 adult patients on the list. This was lower than registered in three large morbidity studies: $21-28$ per 1000 adult patients per year (clinical diagnoses). ${ }^{1.4}$ This indicates considerable overdiagnosing in general practice, especially in patients aged 45 years and older. The chosen objective criterion, A-mode ultrasonography of the maxillary sinus, is quite sensitive and highly specific compared with invasive procedures. Furthermore, maxillary ultrasonography was found to be a reliable procedure.

Ultrasonographically positive frontal sinusitis was rare. Only one case was found in 441 episodes, and this was in conjunction with maxillary sinusitis. The sensitivity of ultrasonography of the frontal sinuses is $90 \%$, which suggests this low incidence of frontal sinusitis is valid. Nevertheless, most patients with maxillary sinusitis, report frontal pain. This symptom does not discriminate between sinusitis and other diagnoses, which may be partly due to the common occurrence of frontal pain in the general population, as found in this study. We conclude that in general practice frontal sinusitis does not deserve an important place in differential diagnosis.

The same discrepancy between the occurrence of disease and the frequency of symptoms was observed for chronic sinusitis and chronic complaints. Chronic sinusitis was defined as a chronic polypous inflammation of the sinus mucosa as assessed by antroscopy.
Only one patient with chronic sinusitis was identified; this patient had recurrent, non-chronic, complaints Persistent complaints occurred more often: half of these patients had chronic headache and nose complaints independent of sinusitis and half had persistent abnormalities of the sinus (empyema, cysts, and polyps).

The prevalence of nose and sinus polyps in this study $(1.5 \%)$ was about the same as found in the general population $(3 \%)$, and in ear, nose, and throat patients $(1 \%) .{ }^{22}{ }^{23}$ Of 40 symptoms and signs presumed to be important for diagnosing sinusitis, five were associated with the results of ultrasonography. Three of these symptoms were also found by Axellson and by Bergthat is, beginning with common cold, purulent nasal secretions, and unilateral maxillary pain. ${ }^{5-9}$ Contrary to the findings in otorhinolaryngology, fever and general weakness seemed not to be important signs in general practice. Most patients with sinusitis feel unwell, but feeling ill does not differentiate between sinusitis and other conditions. Rhinoscopy and inspection of the throat can easily show three rare but important signs: ostial purulent secretions, nasal polyps, or postnasal drip.

\section{ACCURACY OF DIAGNOSIS}

The participating practitioners were uncertain about their clinical diagnoses in one third of the episodes and in $40 \%$ they were correct; underdiagnosis seldom occurred (5\%). Assuming that practitioners always decide on a diagnosis, $55-65 \%$ of their clinical diagnoses would be correct eventually. This result agrees with that of Berg, who found $70 \%$ accuracy of clinical diagnoses by ear, nose, and throat surgeons. ${ }^{9}$

We have proposed an algorithmic rule to confirm or reject the diagnosis sinusitis, based on weighted values of five symptoms. With this algorithm the proportion of correct diagnoses increases from $40 \%$ to $55 \%$, but $25 \%$ remain uncertain. When practitioners do not categorise uncertain diagnoses, about $70 \%$ of definite diagnoses will be correct diagnoses. Either way, incorrect clinical diagnoses have to be accepted. If an algorithmic rule is used false negative diagnoses will equal false positive ones. If doctors decide, they tend to overdiagnose rather than miss cases. The consequences of false positive or false negative diagnosis are unknown because experimental data are lacking.

Ultrasonography does not discriminate purulent from non-purulent secretions. This seems to be a disadvantage but it must be noted that according to the literature one quarter of the purulent sinus secretions can be sterile and half of the non-purulent sinus secretions can grow pathogens. ${ }^{24}$ Purulency should determine the choice of treatment, but this concept is not investigated thoroughly.

\section{CONCLUSIONS}

Our results show that general practitioners see a variety of symptoms, signs, and course of episodes of maxillary sinusitis. The start or the end of a sinusitis episode often cannot be determined precisely, and the symptomatic borders between sinusitis and nose complaints or sinusitis-like pain are not always clear. Though maxillary sinusitis is usually defined as a cavity filled with pus, this rather anatomically oriented definition does not seem to be reflected in the dynamic clinical picture. For the moment, maxillary sinusitis can be looked at by general practitioners as a nosological syndrome, rather than as a disease limited to the rare persistent sinus empyema.

Treatment should continue to be guided by the severity and the duration of symptoms, and by the functional impairments until decisive therapeutical trials have been reported. Research should be aimed at presumed prognostic factors such as purulency of 
secretions, symptom severity, symptom duration, functional status, and similar clinically important markers. It remains to be seen if the diagnosis sinusitis, however defined, is that important for determining treatment and prognosis.

We thank the general practitioners of Almere-Haven group for their collaboration. This study was supported by a grant from the Netherlands Organisation for Scientific Research (NWO), grant number HAG 715111, and a grant from the Praeventiefonds, grant number 28-1415.

\footnotetext{
1 Lamberts $\mathrm{H}$, Brouwer $\mathrm{HJ}$, Mohrs J. Reason for encounter-episode- and processoriented standard output from the transition project. Amsterdam: Department of onented standard output from the transition project. Amsterdam: Depart

2 Lamberts H. In het huis van de huisarts; verslag van het Transitieproject. Lamberts H. In het huis van
Lelystad: Meditekst, 1991 .

Lelystad: Meditekst, 1991.
Van den Hoogen HJM, Huygen FJA, Schellekens JWG, Straat JM, Van der Velden HGM. Morbidity figures from general practice 1978-1982. Nijmegen Nijmeegs Universitair Huisartsen Instituut, 1985.

4 Royal College of General Practitioners, Office of Population Censuses, Department of Health and Social Security. Morbidity statistics from general practice 1981-82. London: HMSO, 1986

5 Axelsson A, Chidekel N. Symptomatology and bacteriology correlated to radiological findings in acute maxillary sinusitis. Acta Otolaryngol 1972;74 $118-22$.

6 Axelsson A, Runze U. Symptoms and signs of acute maxillary sinusitis. Otorhinolaryngology 1976;38:298-308.

7 Axelsson A, Runze U. Comparison of subjective and radiological findings during the course of acute maxillary sinusitis. Ann Otol Rhinol Laryngol 1983;92:75-8.

8 Berg O, Bergstedt $\mathbf{H}$, Carenfelt C, Lind MG, Perols O. Discrimination of purulent from nonpurulent maxillary sinusitis. Ann Otol Rhinol Laryngol 1981;90:272-5.
}

Berg O, Carenfelt $\mathrm{C}$. Analysis of symptoms and clinical signs in the maxillary sinus empyema. Acta Otolaryngol (Stockh) 1988;105:343-9.

10 Revonta $M$. Ultrasound in the diagnosis of maxillary and frontal sinusitis. Acta Otolaryngol 1980;suppl 370:1-54.

11 Jannert M, Andreasson L, Holmer NG, Lörinc P. Ultrasonic examination of the paranasal sinuses. Acta Otolaryngol 1982;suppl 389:29-52.
the

12 Bauer WJ, Bockmeyer M. Endoskopisch kontrollierte Ultraschalldiagnostik der Kieferhohlen. Laryngology Rhinology Otology 1983;62:443-5.

13 Otten FWA, Bouwhuis-Hoogerwerf ML, Grote JJ. Echografie als onderzoekmethode van de sinus maxillaris. Ned TijdschrGeneeskd 1984;128: $1941-4$

14 Vuorinen P, Kauppila A, Pulkkinen K. Comparison of results of röntgen examination and puncture and irrigation of the maxillary sinuses. $f$ Laryngol 1962;76:359-64.

15 McNeill RA. Comparison of the findings on transillumination, $x$-ray and lavage of the maxillary sinus. $\mathcal{F}$ Laryngol Otol 1963;72:1009-13.

16 Illum P, Jeppesen F, Langebaek E. X-ray examination and sinoscopy in maxillary sinus disease. Acta Otolaryngol 1972;74:287-92.

17 Otten FWA, Engberts GER, Grote JJ. Ultrasonography as a method of examination for the frontal sinus. Clin Otolaryngol 1990;16:285-7.

18 Suompää J, Revonta $M$. Diagnosis of frontal sinusitis: one-dimensional ultrasonography versus radiography. F Laryngol Otol 1989;103:765-7.

19 Davidson TM, Brahme FJ, Gallagher ME. Radiographic evaluation for nasal dysfunction: computed tomography versus plain films. Head Neck 1989;11: 405-9.

20 Lloyd GAS, Lund VJ, Scadding GK. CT of the paranasal sinuses and functional endoscopic surgery: a critical analysis of 100 symptomatic functional endoscopic surgery: a critical

21 Albert A, Harris EK. Multivariate interpretation of clinical labmatory data. New York: Marcel Dekker, 1987.

22 Vainio-Matilla J. Correlations of nasal symptoms and signs in a random sampling study. Acta Otolaryngol 1974;suppl 318:1-48.

23 Savolainen S. Allergy in patients with acute maxillary sinusitis. Allergy 1989;44:116-22.

24 Ylikoski J, Savolainen S, Jousimies-Somer $\mathrm{H}$. The bacteriology of acute maxillary sinusitis. Otorhinolaryngology 1989;51:175-81.

(Accepted 22 fuly 1992)
Department of

ology and

Population Sciences,

London School of Hygiene

and Tropical Medicine,

London WC1E 7HT

D A Leon, lecturer in

epidemiology

Swedish Institute for Social Research, S-106 09

Stockholm, Sweden

D Vågerö, reader in medical sociology

Medical Birth Registry, National Board of Health and Social Welfare S-106 30 Stockholm, Sweden

P Otterblad Olausson, section head

Correspondence to:

Dr Leon.

BMF 1992;305:687-91

\title{
Social class differences in infant mortality in Sweden: comparison with England and Wales
}

\author{
D A Leon, D Vågerö, P Otterblad Olausson
}

\section{Abstract}

Objectives - To investigate social class differences in infant mortality in Sweden in the mid-1980s and to compare their magnitude with that of those found in England and Wales.

Design-Analysis of risk of infant death by social class in aggregated routine data for the mid-1980s, which included the linkage of Swedish births to the 1985 census.

Setting-Sweden and England and Wales.

Subjects - All live births in Sweden (1985-6) and England and Wales (1983-5) and corresponding infant deaths were analysed. The Swedish data were coded to the British registrar general's social class schema.

Main outcome measures-Risk of death in the neonatal and postneonatal period.

Results-Taking the non-manual classes as the reference group, in the neonatal period in Sweden the manual social classes had a relative risk for mortality of 1.20 (95\% confidence interval 1.02 to 1.43) and those not classified into a social class a relative risk of $1.08(0.88$ to 1.33$)$. In the postneonatal period the equivalent relative risks were $1.38(1.08$ to 1.77) for manual classes and $2.14(1.65$ to 2.79$)$ for the residual; these are similar to those for England and Wales $(1.43$ (1.36 to 1.51$)$ for manual classes, $2.62(2.45$ to 2.81$)$ for the residual)

Conclusions - The existence of an equitable health care system and a strong social welfare policy in Sweden has not eliminated inequalities in postneonatal mortality. Furthermore, the very low risk of infant death in the Swedish non-manual group (4.8/ 1000 live births) represents a target towards which public health interventions should aim. If this rate prevailed in England and Wales, $63 \%$ of postneonatal deaths would be avoided.

\section{Introduction}

Sweden's record on infant mortality is remarkable. Between 1920 and 1981 it had the lowest reported infant mortality of any country in the world. Between 1982 and 1986 it moved to second or third place behind either Japan or Finland.' This pre-eminent position has been maintained in the face of a continuous decline in infant mortality throughout the developed world, including Sweden itself. ${ }^{2-5}$

Sweden is often regarded as setting a standard to which other countries aspire, as shown by the many studies that have compared rates and trends in other countries with those in Sweden. ${ }^{5-9}$. In addition, the Swedish welfare and health care systems have been scrutinised to glean ideas as to how other countries might reduce infant mortality. ${ }^{10}$

There has been less awareness internationally of the existence of socioeconomic differences in infant mortality within Sweden. Regional differences in infant mortality were large in the early parts of this century but have since declined substantially. ${ }^{24}$ Socioeconomic differences, unlike regional ones, have not been routinely monitored. The paucity of information on this subject has encouraged the assumption that, today, socioeconomic differences in infant mortality do not exist in Sweden or other Scandinavian countries. ${ }^{112}$

A recent, widely read review of inequalities in health stated that "the conclusion, expressed by many [is] that social inequalities in health in early life are negligible in Sweden, at least in those areas where information is available."13

Several studies of socioeconomic differences in birth outcome in Sweden have been published ${ }^{14-18}$ but, as discussed below, they have several limitations. Our study focuses on inequalities in infant mortality in Sweden, placing them in the context of Britain, a 